\title{
Enzymatic saccharification of shrub willow genotypes with differing biomass composition for biofuel production
}

\section{Michelle J. Serapiglia1, Michele C. Humiston ${ }^{2}$, Haowen $\mathrm{Xu}^{3}$, David A. Hogsett ${ }^{3}$, Ramón M. de Orduña ${ }^{2}$, Arthur J. Stipanovic ${ }^{4}$ and Lawrence B. Smart ${ }^{1}{ }^{*}$}

${ }^{1}$ Department of Horticulture, New York State Agricultural Experiment Station, Cornell University, Geneva, NY, USA

2 Department of Food Science, New York State Agricultural Experiment Station, Cornell University, Geneva, NY, USA

${ }^{3}$ Mascoma Corporation, Lebanon, NH, USA

${ }^{4}$ Department of Chemistry, State University of New York College of Environmental Science and Forestry, Syracuse, NY, USA

Edited by:

Samuel P. Hazen, University of Massachusetts, USA

\section{Reviewed by:}

Chen Hongzhang, Chinese Academy of Sciences, China

Marcia R. Braga, Instituto de

Botânica, Brazil

\section{*Correspondence:}

Lawrence B. Smart, Department of Horticulture, New York State Agricultural Experiment Station, Cornell University, 630 West North Street, Geneva, NY 14456, USA. e-mail: Ibs33@cornell.edu
In the conversion of woody biomass feedstocks into liquid fuel ethanol, the pretreatment process is the most critical and costly step. Variations in biomass composition based on genetic differences or environmental effects have a significant impact on the degree of accessibility accomplished by pretreatment and subsequent sugar release by enzymatic hydrolysis. To evaluate this, biomass from 10 genetically diverse, genotypes of shrub willow (Salix spp.) was pretreated with a hot-water process at two levels of severity, hydrolyzed using a combination of two commercial enzyme cocktails, and the release of hexose and pentose monomers was quantified by high-performance liquid chromatography. Among the genotypes selected for analysis, cellulose content ranged from 39 to $45 \%(\mathrm{w} / \mathrm{w})$ and lignin content ranged from 20 to $23 \%(\mathrm{w} / \mathrm{w})$ at harvest. Differences in the effectiveness of the pretreatment process were observed among the various willow genotypes. Correlations were identified between total sugar release and \% cellulose and \% lignin content. There was a significant effect of pretreatment severity on polysaccharide accessibility, but the response to pretreatments was different among the genotypes. At the high severity pretreatment 'SV1' was the least recalcitrant with sugar release representing as much as $60 \%$ of total biomass. These results suggest that structural, as well as chemical characteristics of the biomass may influence pretreatment and hydrolytic efficiency.

Keywords: bioenergy, biomass, ethanol, hydrolysis, Salix

\section{INTRODUCTION}

The reduction of US dependency on foreign oil will require the production of domestic renewable transportation fuels from lignocellulosic biomass as alternative energy sources. The Energy Independence Security Act of 2007 has mandated an increase in the renewable fuel standard to 36 billion gallons of renewable fuels by 2022 (H.R., 2007). To reach this goal within the next decade and prevent competition for food crops such as corn, the conversion processes of lignocellulosic biomass into fermentation products, such as ethanol or butanol has to be improved. Dedicated energy crops, including perennial grasses and short-rotation woody crops, such as hybrid poplar (Populus spp.) and shrub willow (Salix spp.), will be crucial in the economic viability of renewable fuel production.

The feasibility of generating biofuels from lignocellulosic energy crops is largely dependent on cost reductions throughout the production cycle and conversion process. Converting lignocellulosic material into ethanol involves four major steps: pretreatment, hydrolysis, fermentation, and product purification or distillation (Lynd, 1996). Pretreatment processes break apart the highly recalcitrant lignocellulosic material mechanically or chemically to make cellulose and hemicelluloses more accessible for hydrolysis. This requires a large amount of energy and is the most expensive step both economically and energetically (Lynd, 1996; Himmel et al., 2007; Yang and Wyman, 2008). Overcoming this recalcitrance and improving cellulose digestibility are key research areas for making cellulosic ethanol profitable and involve improvements in pretreatments and hydrolysis. However, there is also potential for cost reductions by identifying and breeding feedstocks with improved sugar release capabilities that are optimal for biofuel production (Guo et al., 2009; Brereton et al., 2010).

Shrub willow bioenergy crops have many desirable characteristics for feedstock and biomass production. With their coppicing ability and vigorous juvenile growth they can produce high biomass yield (>11 odt (oven dried tonnes) $\mathrm{ha}^{-1}$ year $^{-1}$ ) on marginal land not suitable for conventional food crops (Volk et al., 2011). Since there has been little cultivation and domestication of shrub willow crops, there is a broad genetic resource available for breeding and a high level of genetic diversity to utilize in the genus Salix, consisting of over 300 species. Selection for pest and disease resistance and improvements in yield has been successful in Sweden, UK, and US (Ahman and Larsson, 1994; Karp et al., 2011; Höglund et al., 2012; Serapiglia et al., 2012).

It has been shown that shrub willow has high phenotypic variation for biomass composition (Serapiglia et al., 2009), owing to differences in cell wall characteristics. Several studies have shown a relationship between lower lignin content in the biomass and improved sugar release, indicating that lignin contributes to the recalcitrance of the cell wall (Chen and Dixon, 2007; Jackson et al., 2008; Studer et al., 2011). However, lignin content is not the only 
contributing factor for sugar release. Further research is required to elucidate the impact of cell wall chemistry and its components on polysaccharide accessibility to improve breeding strategies.

In this study, we investigated the biomass compositional variation among 30 unique genotypes of shrub willow planted at a single site and examined sugar release following enzymatic hydrolysis of untreated biomass. Further examination of 10 selected genotypes included a hot-water pretreatment at two severity levels followed by enzymatic saccharification to quantify sugar release and the conversion to ethanol utilizing a simultaneous saccharification and fermentation (SSF) method. The goal of this project was to determine if differences in biomass compositional characteristics among genotypes of shrub willow affect the release of sugars from enzymatic saccharification and the conversion efficiency to ethanol.

\section{MATERIALS AND METHODS SOURCE MATERIAL AND BIOMASS COLLECTION}

Thirty genotypes of willow were hand planted in May 2006 using $25-\mathrm{cm}$ cuttings in double row spacing in four completely randomized blocks in the 2006 Yield Trial in Constableville, NY, USA (Table 1). The trial was coppiced at the end of the first growing season, and after the third post-coppice season, willow stems were harvested in December 2009. Stems were chipped and the four replicates pooled. Biomass yield was measured and a sub-sample was collected, dried, and weighed to determined moisture content at harvest, which allowed estimation of dry weights. For this, chips were dried to a constant weight at $60^{\circ} \mathrm{C}$ and ground in a Wiley mill through a 20 -mesh screen. Further fine milling to $0.5 \mathrm{~mm}$ particle size was performed using an MF 10 analytical mill (IKA, Wilmington, NC, USA). In addition, a $25-\mathrm{cm}$ section was collected from the middle of a typical canopy stem of one plant in each plot to determine wood density by volumetric displacement (TAPPI Standard T 258 om-06, 2006).

\section{HIGH-RESOLUTION THERMOGRAVIMETRIC ANALYSIS}

Unextracted willow biomass samples were analyzed by thermogravimetric analysis (Thermogravimetric Analyzer 2950, TA Instruments, New Castle, DE, USA with TA Universal Analysis 2000 software) according to Serapiglia et al. (2009). Each biomass sample was analyzed with three instrumental replicates. Results obtained from this analysis were expressed as \% cellulose, hemicelluloses, lignin, and ash as a proportion of total dry biomass.

\section{HOT-WATER PRETREATMENT}

Dried, unextracted, ground biomass was soaked to saturation in water overnight at $4^{\circ} \mathrm{C}$. All samples were filtered through Büchner funnels with $15 \mathrm{~cm}$ Whatman filters (grade 1). Dry weight was determined in triplicate by drying sub-samples of approximately $2 \mathrm{~g}$ overnight at $105^{\circ} \mathrm{C}$. The willow biomass at a solid loading of $20 \%(\mathrm{w} / \mathrm{w})$ with water was pretreated in 316 stainless steel tube reactors fitted with 316 stainless steel caps (Swagelok, USA) to prevent evaporation of the liquid fraction. All samples were pretreated at $200^{\circ} \mathrm{C}$ in a fluidized sand bath (Techne Precision, USA) with two different resonance times of 5 and $9 \mathrm{~min}$, allowing for 5 min of heat-up time. All samples were pretreated in duplicate.
Table 1 | Shrub willow genotypes used in this study harvested from the 2006 Constableville yield trial.

\begin{tabular}{|c|c|c|}
\hline $\begin{array}{l}\text { Clone ID/ } \\
\text { cultivar } \\
\text { epithet }\end{array}$ & Species/pedigree & Source \\
\hline 'SV1' & Salix $\times$ dasyclados & University of Toronto \\
\hline 'SX61' & S. sachalinensis & University of Toronto \\
\hline 'SX64' & S. miyabeana & University of Toronto \\
\hline 'S25' & S. eriocephala & University of Toronto \\
\hline 94001 & S. purpurea & Blossvale, NY \\
\hline $9832-49$ & S. eriocephala & Bred in 1998 \\
\hline 9837-77 & S. eriocephala & Bred in 1998 \\
\hline 00X-026-082 & S. eriocephala & Bred in 2000 \\
\hline 00X-032-094 & S. eriocephala & Bred in 2000 \\
\hline 'Fish Creek' & S. purpurea & Bred in 1998 \\
\hline 'Wolcott' & S. purpurea & Bred in 1998 \\
\hline 'Onondaga' & S. koriyanagi $\times$ S. purpurea & Bred in 1999 \\
\hline 'Allegany' & S. koriyanagi $\times$ S. purpurea & Bred in 1999 \\
\hline 'Oneonta' & S. purpurea $\times$ S. miyabeana & Bred in 1998 \\
\hline 'Oneida' & S. purpurea $\times$ S. miyabeana & Bred in 1999 \\
\hline 'Millbrook' & S. purpurea $\times$ S. miyabeana & Bred in 1999 \\
\hline 'Saratoga' & S. purpurea $\times$ S. miyabeana & Bred in 1999 \\
\hline 'Sherburne' & S. sachalinensis $\times$ S. miyabeana & Bred in 1998 \\
\hline 'Canastota' & S. sachalinensis $\times$ S. miyabeana & Bred in 1999 \\
\hline 'Cicero' & S. sachalinensis $\times$ S. miyabeana & Bred in 1998 \\
\hline 'Marcy' & S. sachalinensis $\times$ S. miyabeana & Bred in 1998 \\
\hline 'Preble' & $\begin{array}{l}\text { S. viminalis } \times(\text { S. sachalinensis } \times \\
\text { S. miyabeana) }\end{array}$ & Bred in 2001 \\
\hline 'Otisco' & S. viminalis $\times$ S. miyabeana & Bred in 1999 \\
\hline 'Verona' & S. viminalis $\times$ S. miyabeana & Bred in 1999 \\
\hline ‘Tully & S. viminalis $\times$ S. miyabeana & Bred in 1999 \\
\hline \multicolumn{3}{|l|}{ Champion' } \\
\hline 'Fabius' & S. viminalis $\times$ S. miyabeana & Bred in 1999 \\
\hline 'Taberg' & S. viminalis $\times$ S. miyabeana & Bred in 1999 \\
\hline 'Erie' & S. viminalis $\times$ S. miyabeana & Bred in 1999 \\
\hline 'Truxton' & S. viminalis $\times$ S. miyabeana & Bred in 1999 \\
\hline 'Owasco' & S. viminalis $\times$ S. miyabeana & Bred in 1999 \\
\hline
\end{tabular}

Rapid cooling was achieved by quenching all reactors in an ice bath for $10 \mathrm{~min}$. All samples were transferred to storage containers. Moisture content and total solids was determined for all samples before continuing with enzymatic hydrolysis or ethanol production. The pretreatment was adjusted to a $\log R_{0}$ severity of 3.6 and 3.9 (Eq. 1). Severity was defined as

$$
R_{0}=t \cdot \mathrm{e}^{\frac{T-100}{14.75}}
$$

where $t$ is the time (minute) and $T$ the temperature $\left({ }^{\circ} \mathrm{C}\right)$. 


\section{ENZYMATIC HYDROLYSIS}

Enzymatic hydrolysis was performed with non-pretreated, nonextracted biomass from all 30 willow genotypes and with pretreated biomass from 10 selected genotypes according to an established National Renewable Energy Laboratory (NREL) protocol (Selig et al., 2008). For the non-pretreated biomass samples, $200 \mathrm{mg}$ of dry biomass was added to $20 \mathrm{~mL}$ scintillation vials. For the pretreated biomass, wet biomass equivalent to $200 \mathrm{mg}$ dry biomass was used. Five milliliters of a $0.1-\mathrm{M}$ sodium citrate buffer $(\mathrm{pH} 5)$ and $500 \mu \mathrm{L}$ of a $100-\mu \mathrm{g} \mathrm{mL}-1$ natamycin solution were added to all samples. Two commercially produced enzyme mixes were used for hydrolysis: $100 \mu \mathrm{L}$ of Cellic ${ }^{\circledR}$ CTec2 (Novozymes, Wilmington, DE, USA), which is a blend of cellulases, $\beta$-glucosidases, and hemicellulase and $20 \mu \mathrm{L}$ of Cellic ${ }^{\circledR}$ HTec2 (Novozymes), which contains additional endoxylanases. All samples were brought to $10 \mathrm{~mL}$ total volume using deionized water. The samples were capped and placed in a shaker-water bath at $50^{\circ} \mathrm{C}$ for $48 \mathrm{~h}$ at $200 \mathrm{rpm}$. Following incubation, samples were filter sterilized $(0.45 \mu \mathrm{m}$ nylon, Grace, Deerfield, IL, USA) for sugar analysis. The collected dry biomass was weighed, and sub-samples were collected for moisture and total solid determination.

\section{SUGAR OUANTIFICATION}

Sugars were quantified by high-performance liquid chromatography (HPLC) using a Shimadzu Prominence System (Columbia, MD, USA) consisting of a DG-20A3 in-line degasser, LC-20AB binary pump, SIL-10AD auto-sampler, CTO-20AC column oven, and RID-10A refractive index detector. Following filtration ( $0.22 \mu \mathrm{m}$, nylon membrane, Whatman) $20 \mu \mathrm{L}$ sample was injected and separated using a sulfonated styrene-divinylbenzene stationary phase $(300 \mathrm{~mm} \times 7.8 \mathrm{~mm}$ i.d., Aminex HPX-87P, Bio-Rad, Hercules, CA, USA) preceded by a cartridge type pre-column (30 $\mathrm{mm} \times 4.6 \mathrm{~mm}$ i.d., de-ashing phase, Bio-Rad) at $85^{\circ} \mathrm{C}$. The mobile phase consisted of ASTM Class I water (Arium 611UV, Sartorius, Germany) and the flow rate was $0.5 \mathrm{~mL} \mathrm{~min}^{-1}$. Data analysis was carried out using the software supplied (LC Solution v.1.23, Shimadzu).

\section{ETHANOL PRODUCTION BY SSF}

Simultaneous saccharification and fermentation was performed on pretreated biomass from 10 selected genotypes. Fermentation studies were performed at a $20-\mathrm{mL}$ scale in sealed serum bottles using unextracted, non-dried pretreated material at a final concentration of $50 \mathrm{~g} \mathrm{~L}^{-1}$ (oven dried basis). A medium comprised of $12 \mathrm{~g} \mathrm{~L}^{-1}$ corn steep liquor and $0.5 \mathrm{~g} \mathrm{~L}^{-1}$ diammonium phosphate, buffered by $50 \mathrm{mM}$ acetate and adjusted to an initial $\mathrm{pH}$ of 5.5 , was used. Penicillin $G$ was added at a final concentration of $30 \mu \mathrm{g} \mathrm{mL}^{-1}$ to inhibit potential bacterial contaminants. Hydrolysis was accomplished through the addition of $60 \mu \mathrm{L}$ Cellic ${ }^{\circledR}$ CTec2 and $6 \mu \mathrm{L} \mathrm{Cellic}{ }^{\circledR} \mathrm{HTec} 2$. An engineered, xylose-fermenting strain of Saccharomyces cerevisiae (Mascoma Corporation) was inoculated at $0.5 \mathrm{~g} \mathrm{~L}^{-1}$ dry cell weight (DCW) for fermentation at $35^{\circ} \mathrm{C}$ at $150 \mathrm{rpm}$. After 73 and $120 \mathrm{~h}$ of fermentation, samples were withdrawn, filtered, acidified, and analyzed by HPLC for ethanol, organic acids, and sugar monomers using an Agilent 1100 System with a refractive index detector (Santa Clara, CA, USA). All samples were separated on an Aminex HPX-87H column with a mobile phase consisting of $0.01 \mathrm{~N}$ sulfuric acid with a flow rate of $0.6 \mathrm{~mL} \mathrm{~min}^{-1}$ (Sluiter et al., 2008). All samples were analyzed using ChemStation (Agilent).

\section{STATISTICAL ANALYSIS}

All statistical analyses were performed using SAS ${ }^{\circledR}$ version 9.2 at a critical $\alpha=0.05$ (SAS Institute Inc., 2000-2004). SAS PROC UNIVARIATE was used to summarize the data distribution for all variables analyzed. PROC GLM was used to perform analysis of variance. When a significant difference $(P<0.05)$ was observed, Tukey's mean studentized range test was used for pairwise comparisons. PROC CORR was used to identify any significant correlations among variables obtained in this study.

\section{RESULTS}

\section{BIOMASS COMPOSITION AND WOOD DENSITY}

All compositional traits were significantly different $(P<0.05)$ by genotype (Figure 1). Cellulose showed the greatest variation among the genotypes ranging from 38 to $45 \%$. 'Tully Champion' had the greatest cellulose content with low lignin, hemicelluloses, and ash content. The lowest lignin content was observed in 'Allegany.' The ash content was $<3 \%$ of the total biomass in all cultivars. Wood density was significantly different by genotype with 'SV1' having the greatest density at $0.48 \mathrm{~g} \mathrm{~cm}^{-3}$ (Figure 2). Density ranged from 0.48 to $0.35 \mathrm{~g} \mathrm{~cm}^{-3}$.

\section{SUGAR RELEASE OF UNTREATED AND PRETREATED BIOMASS}

Sugar release from untreated biomass was minimal, but there were significant differences by genotype (Figure 3). Based on this evaluation, 10 genotypes were selected for further analysis. Hotwater pretreatments improved sugar release in all experiments in a genotype-specific fashion (Figure 4). Except for 'SX61,' hot-water pretreatment with the 3.9 severity lead to greater sugar yields. The greatest sugar yield was observed in 'SV1' after the higher severity pretreatment of 3.9. After the 3.6 severity pretreatment, 'Fabius' had the greatest sugar released and only a small increase in sugar release was observed when the pretreatment severity was increased. For 'SX61,' there was no significant difference between the two pretreatment times.

\section{ETHANOL PRODUCTION BY SSF}

Ethanol production was significantly different by genotype with the greatest ethanol yield from 'SX64' and 'SV1' (Figure 5). The increase in fermentation time from 73 to $120 \mathrm{~h}$ showed a significant increase in ethanol production across all genotypes, except for 'Preble.'

\section{CORRELATIONS BETWEEN THE TRAITS}

For the 30 genotypes studied in this trial there was a strong negative correlation between cellulose content and lignin content, with a correlation coefficient $R^{2}=-0.80$ (Figure 6). A weaker correlation was identified between cellulose content and sugar yields from the pretreatment with the higher severity with a correlation coefficient $R^{2}=0.60$. Ethanol yields correlated positively with sugar yields $\left(R^{2}=0.74\right)$ and wood density $\left(R^{2}=0.55\right)$. 


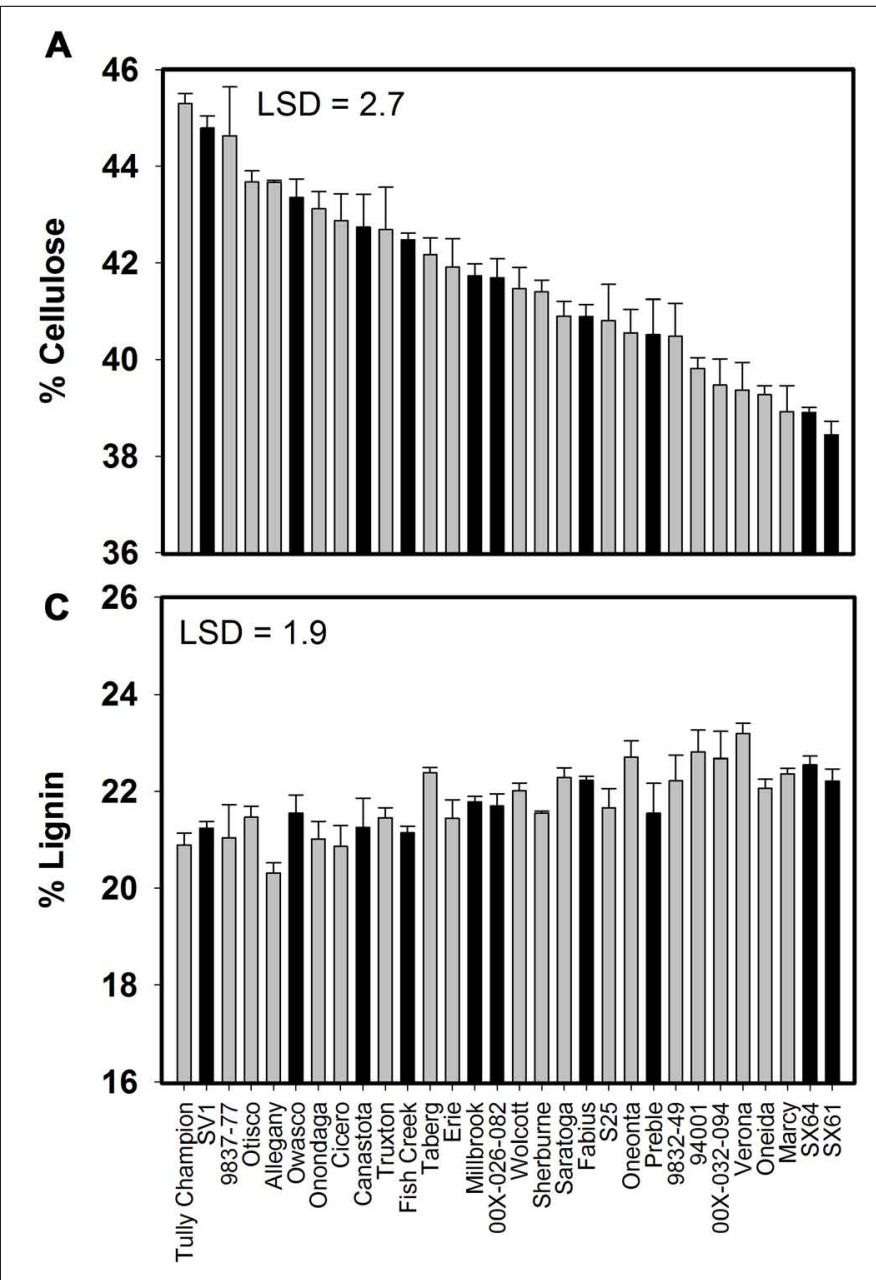

Genotype

FIGURE 1 | Willow composition as percent dry weight (mean \pm SE of three replicates) at harvest after 3 years of growth at Constableville, NY, USA as determined by high-resolution thermogravimetric analysis. Black
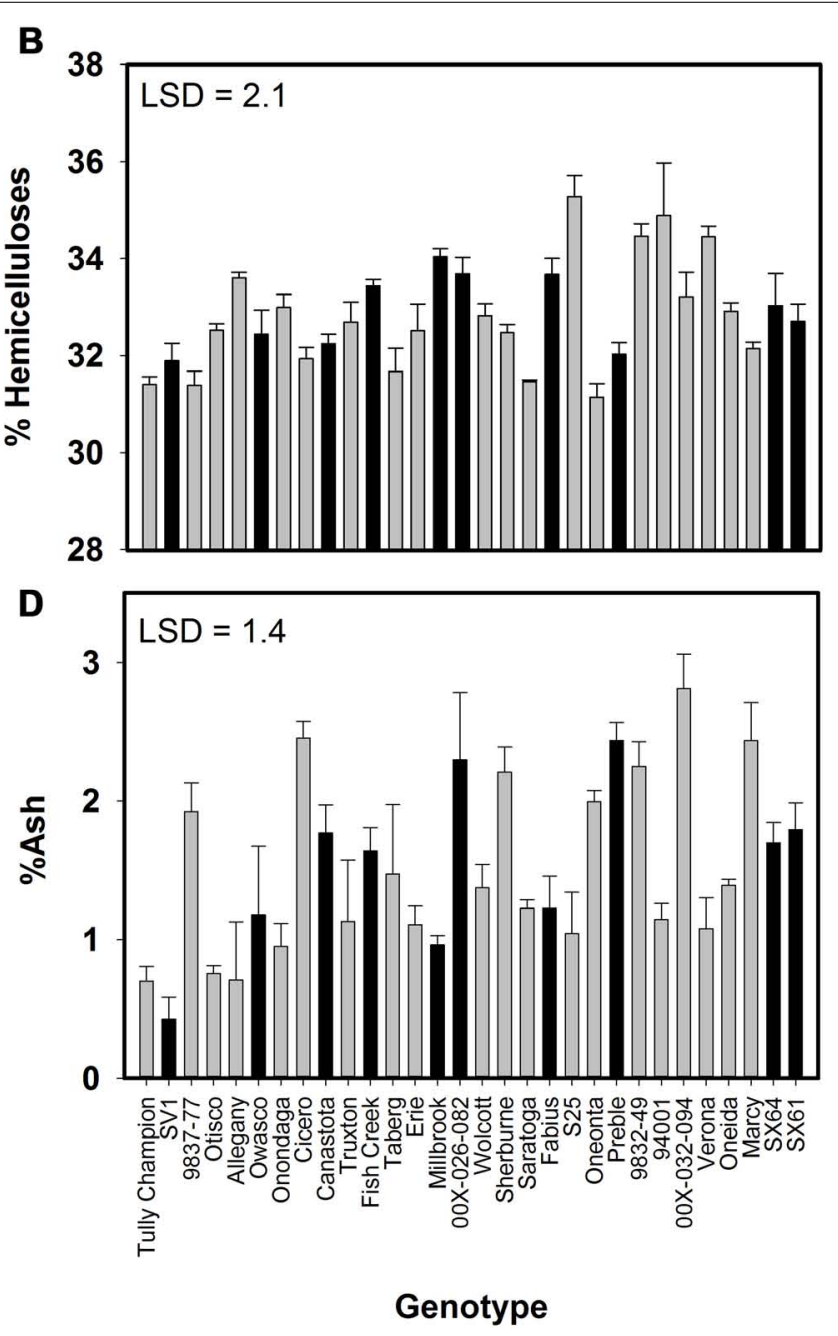

bars indicate 10 genotypes selected for pretreatment. (A) Cellulose, (B) hemicelluloses, (C) lignin, and (D) ash. Least significant differences (LSDs) from Tukey's studentized range test are indicated on each graph.

\section{DISCUSSION}

To identify a relationship between biomass composition and sugar yield, biomass from shrub willow genotypes representing a range of compositional traits were pretreated using a hot-water method, and sugars were hydrolyzed enzymatically. In this study, enzymatic hydrolysis was performed with excess enzyme concentrations to reveal differences in biomass recalcitrance. Large differences in sugar yield were observed for the untreated biomass and for the two different pretreatment severities. These analyses were performed on bulk biomass samples including the bark, since commercial conversion facilities will utilize willow wood chips harvested with the bark. Bark is known to have a diversity of extractives and phenolic compounds present in greater levels than in debarked wood, many of which can act as fermentation inhibitors (Jonsson et al., 1998; Robinson et al., 2002).

The range of compositional differences among the willow genotypes examined in this study was rather modest, 38.4-45.3\% for cellulose, $31.1-34.9 \%$ for hemicelluloses, and $20.3-23.2 \%$ for lignin. In comparison, other recent studies have examined willow with cellulose content ranging from 34.8 to $41.8 \%$ and lignin ranging from 23.9 to $28.8 \%$ (Ray et al., 2012) or lignin content ranging from 15.7 to $27.9 \%$ in Populus trichocarpa (Studer et al., 2011). Selecting a larger and more diverse group of genotypes growing on more than one site may have increased the range in compositional variation used in this study. Although differences in recalcitrance and improved sugar release have been identified among natural variants (Studer et al., 2011; Ray et al., 2012), those differences are more dramatic in plants engineered to have greatly reduced lignin content (Chen and Dixon, 2007; Fu et al., 2011; Coleman et al., 2012; Mansfield et al., 2012; Pattathil et al., 2012). The extremes of lignin content have been extended through genetic engineering to contents as low as $10 \%$ in Populus, resulting in dramatic differences in enzymatic hydrolysis characteristics (Mansfield et al., 2012). Within the range of compositional variation of non-genetically engineered willows, the differences in accessibility to hydrolytic enzymes may be due to more complex 


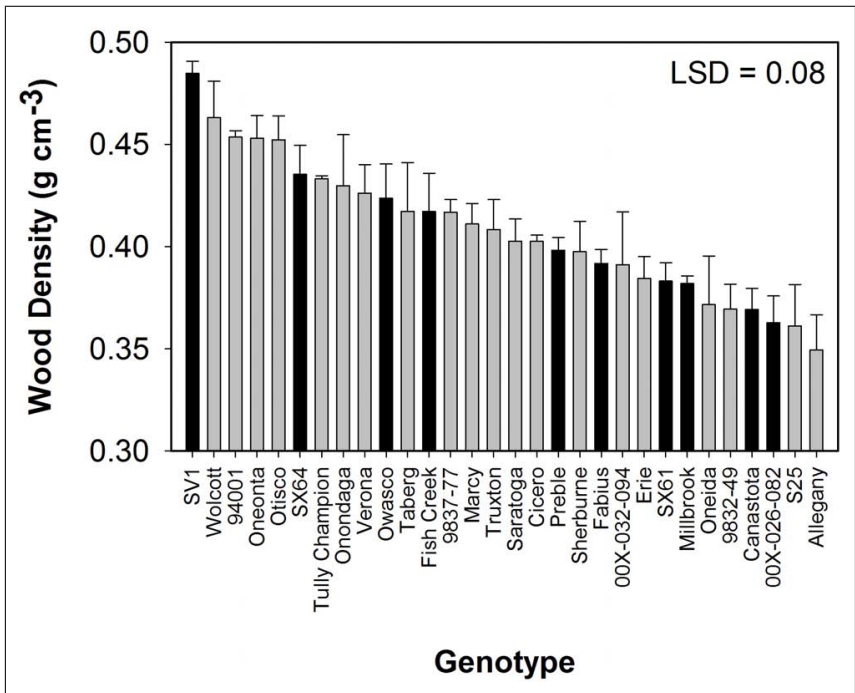

FIGURE 2 | Wood density (mean \pm SE of three replicates) from 3 year growth at Constableville, NY, USA. Black bars indicate 10 genotypes selected for pretreatment. Least significant difference (LSD) from Tukey's studentized range test is indicated.

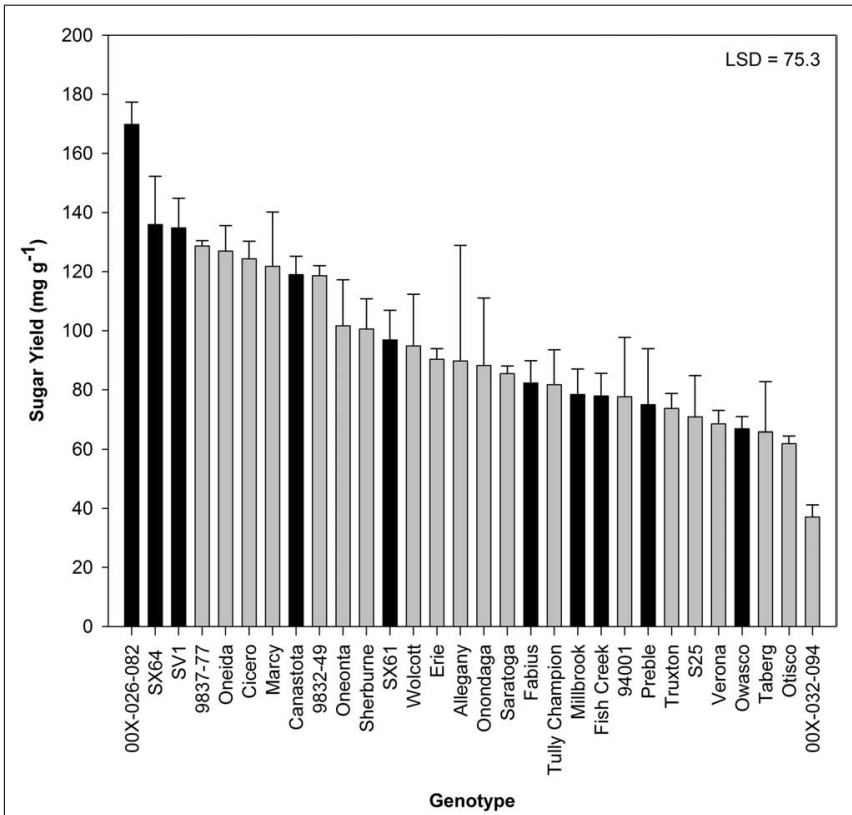

FIGURE 3 | Total sugar released (mean \pm SE of three replicates) after enzymatic hydrolysis on untreated biomass. Black bars indicate 10 genotypes selected for pretreatment. Least significant difference (LSD) from Tukey's studentized range test is indicated.

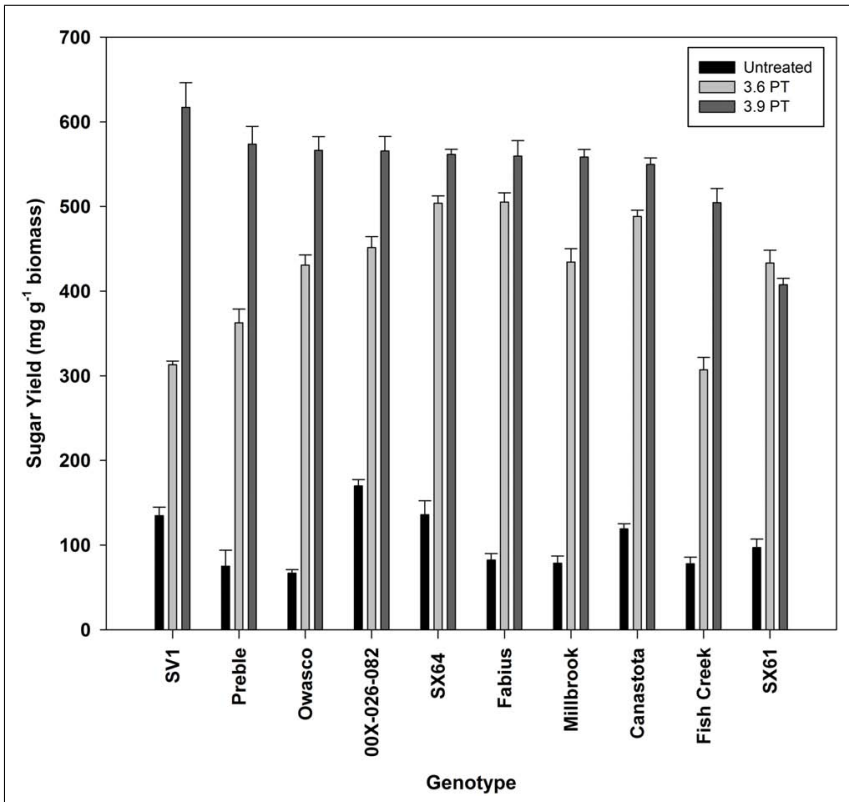

FIGURE 4 | Total sugar released (mean \pm SE of three replicates) after enzymatic hydrolysis on untreated and hot-water pretreated biomass.

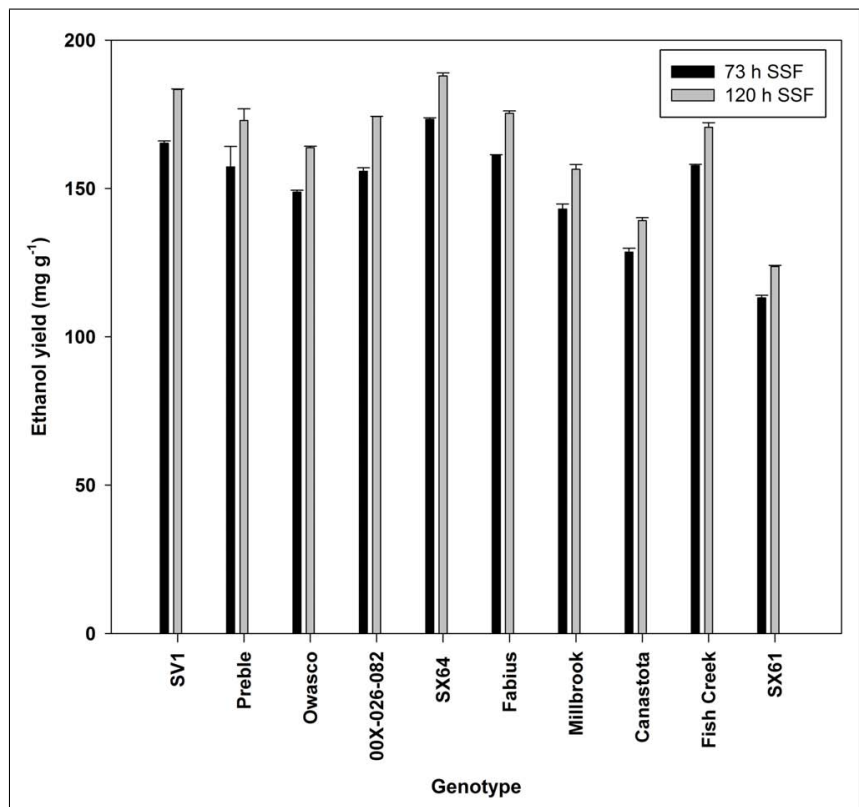

FIGURE 5 | Ethanol yield (mean \pm SE of three replicates) from simultaneous saccharification and fermentation after two incubation times.

was glucose (data not shown), but neither total sugar yield nor glucose yield was correlated with biomass composition or wood density, indicating that the total sugar content in the biomass is not the primary contributing factor for sugar availability in untreated biomass. The genotype 00X-026-082 had the highest sugar yield and only moderate levels of cellulose and hemicelluloses. The very low sugar yield observed in 00X-032-094 was due to undetectable levels of glucose. It was the only genotype to 

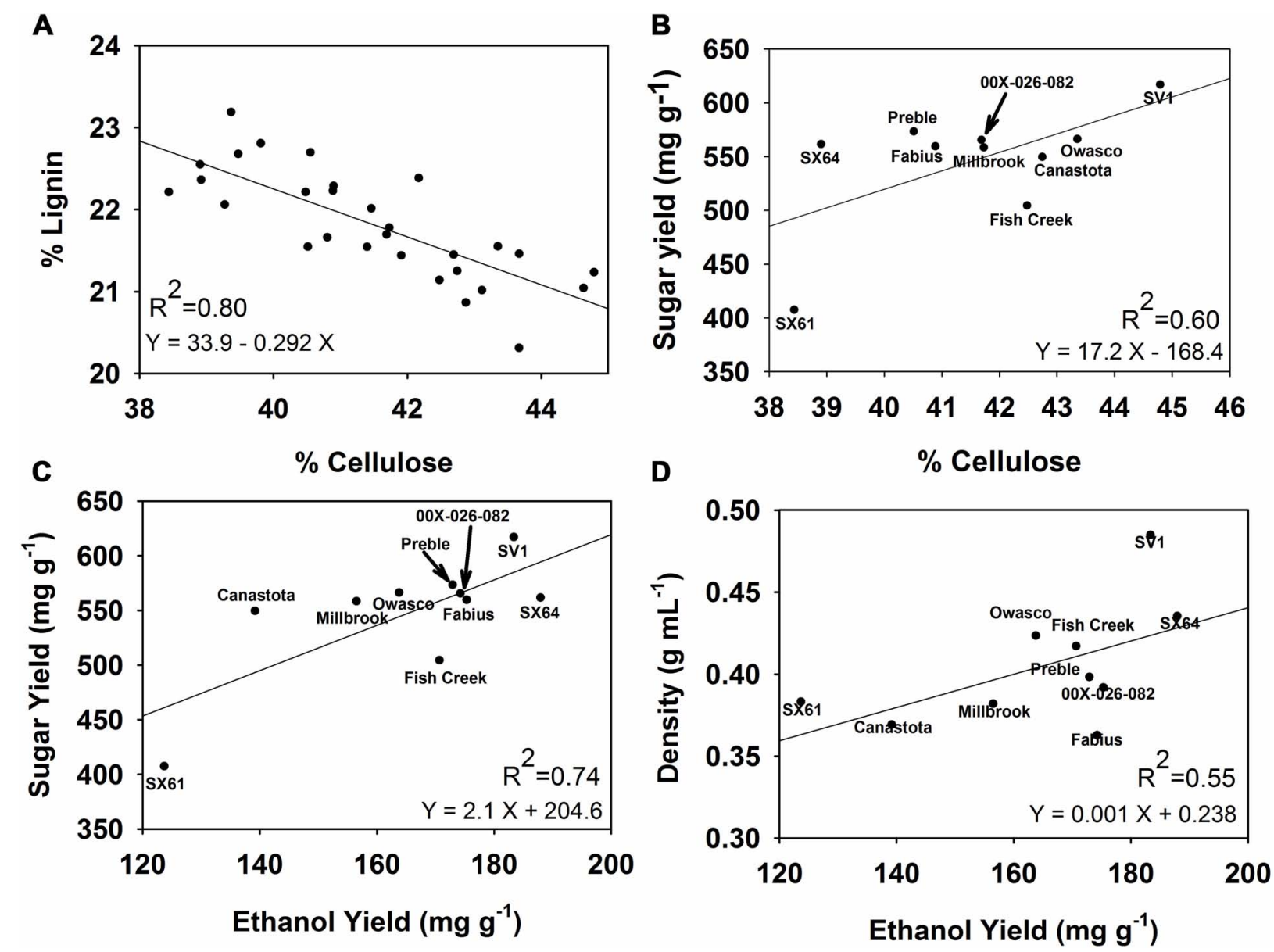

FIGURE 6 | Correlations observed among woody biomass traits, sugar release, and ethanol yield. (A) \% Lignin vs. \% cellulose, (B) total sugar yield vs. \% cellulose, (C) total sugar yield vs. ethanol yield, and (D) wood density vs. ethanol yield.

release no glucose monomers. It is unclear whether glucose was released and immediately degraded or if it never was a product of hydrolysis.

The hot-water pretreatment significantly improved the accessibility of the cell walls to enzymatic digestion, leading to three to five times greater sugar yields compared with untreated biomass. Sugar yields observed for willow in this study were comparable to those observed for poplar subjected to a similar pretreatment severity (Studer et al., 2011). Sugar yield following the higher severity pretreatment was dependent on cellulose content in the biomass, based on the observed correlation (Figure 6), as was observed among European willow genotypes (Brereton et al., 2010). This suggests that breeding for differences in biomass composition could have an impact on sugar availability for fermentation. 'SV1' which has the greatest cellulose content $(44.8 \%)$ released the most sugar following the 3.9 severity pretreatment, $617 \mathrm{mg} \mathrm{g}^{-1}$ biomass, equivalent to $80 \%$ recovery. However, cellulose content alone cannot be the only factor impacting sugar release, since some of the genotypes with low cellulose content had high sugar yield, such as 'Preble.' Other factors influencing recalcitrance and sugar release include cell wall chemistry, such as phenolic groups in the lignin (Lapierre et al., 2000), S:G ratios in the lignin (Studer et al., 2011), and cell wall structural variability dependent on tissue types (Dinus et al., 2001).

The differences in sugar release between the two different pretreatment severities provided insight into the recalcitrance of the willow genotypes. To reduce costs associated with biomass conversion, it would be highly beneficial to utilize feedstocks that have high sugar release following pretreatments with a lower severity. In this study, the less severe pretreatment of $10 \mathrm{~min}$ resulted in the greatest sugar yield from 'SX64' and 'Fabius,' while there was only a small increase in sugar release (from 70 to $80 \%$ recovery) when the biomass was exposed to the more severe pretreatment. These two genotypes were less recalcitrant than 'SV1,' which required the severe pretreatment to release most of the sugars.

Fermentation to ethanol produced $50 \%$ of the theoretical ethanol yield from 'SX64' and 'SV1.' Sassner et al. (2008) reported ethanol yields with willow from simultaneous SSF reaching 76\% of the theoretical yield. A positive correlation with wood density was also identified. There is only limited research examining the relationship between wood density and sugar release or conversion 
to ethanol. A recent study examining sugar recovery following pretreatment and enzymatic hydrolysis from high and low density genotypes of 0.48 and $0.40 \mathrm{~g} \mathrm{~cm}^{-3}$, respectively, resulted in greater sugar recovery from the low density genotype (Martin et al., 2011; Djioleu et al., 2012). However, only two genotypes were examined making it difficult to statistically identify a relationship between wood density and sugar release. Wood density is driven by fiber traits such as fiber lumen diameters, fiber wall to lumen ratios, and total wall areas (Dinus, 2001; Martinez-Cabrera et al., 2009), so further studies considering the cell ultrastructure and wood anatomy of shrub willow are necessary to understand the relationships between wood density, sugar release, and ethanol yield.

Overall this study has shown significant variation in biomass composition, differences in sugar yield and recalcitrance to pretreatment, and differences in ethanol yield among the shrub willow genotypes. Relationships between sugar release and cellulose

\section{REFERENCES}

Ahman, I., and Larsson, S. (1994). Genetic improvement of willow (Salix) as a source of bioenergy. Norw. J. Agric. Sci. 18S, 47-56.

Brereton, N. J. B., Pitre, F. E., Hanley, S., Ray, M. J., Karp, A., and Murphy, R. J. (2010). QTL mapping of enzymatic saccharification in short rotation coppice willow and its independence from biomass yield. Bioenergy Res. 3, 251-261.

Chen, F., and Dixon, R. A. (2007). Lignin modification improves fermentable sugar yields for biofuel production. Nat. Biotechnol. 25, 759-761.

Coleman, H. D., Cánovas, F. M., Man, H., Kirby, E. G., and Mansfield, S. D. (2012). Enhanced expression of glutamine synthetase (GSla) confers altered fibre and wood chemistry in field grown hybrid poplar (Populus tremula $\times$ alba $)(717-1 \mathrm{~B} 4)$. Plant Biotechnol. J. 10, 883-889.

Dinus, R. (2001). Genetic improvement of poplar feedstock quality for ethanol production. Appl. Biochem. Biotechnol. 91-93, 23-34.

Dinus, R. J., Payne, P., Sewell, M. M., Chiang, V. L., and Tuskan, G. A. (2001). Genetic modification of short rotation poplar wood: properties for ethanol fuel and fiber productions. Crit. Rev. Plant Sci. 20, 51-69.

Djioleu, A. C., Arora, A., Martin, E. M., Smith, J. A., Pelkki, M. H., and Carrier, D. J. (2012). Sugar recovery from the pretreatment/enzymatic hydrolysis of high and low specific gravity poplar clones. Agric. Food Anal. Bacteriol. 2, 121-131.

Fu, C., Mielenz, J. R., Xiao, X., Ge, Y., Hamilton, C. Y., Rodriguez, M., et al. (2011). Genetic manipulation of lignin reduces recalcitrance and improves ethanol production from switchgrass. Proc. Nat. Acad. Sci. U.S.A. 108, 3803-3808.

Guo, G.-L., Hsu, D.-C., Chen, W.H., Chen, W.-H., and Hwang, W.-S. (2009). Characterization of enzymatic saccharification for acidpretreated lignocellulosic materials with different lignin composition. Enzyme Microb. Technol. 45, 80-87.

Himmel, M. E., Ding, S.-Y., Johnson, D. K., Adney, W. S., Nimlos, M. R., Brady, J. W., et al. (2007). Biomass recalcitrance: engineering plants and enzymes for biofuel production. Science 315, 804-807.

Höglund, S., Rönnberg-Wästljung, A., Lagercrantz, U., and Larsson, S. (2012). A rare major plant QTL determines non-responsiveness to a gallforming insect in willow. Tree Genet.

H.R. (2007). 6-110th Congress: Energy Independence and Security Act of 2007. Available at: www.GovTrack.us. [retrieved March 12, 2013] from http://www.govtrack.us/congress/

Jackson, L. A., Shadle, G., Zhou, R., Nakashima, J., Chen, F., and Dixon, D. A. (2008). Improving saccharification efficiency of alfalfa stems through modification of the terminal stages of monolignol biosynthesis. Bioenergy Res. 1, 180-192.

Jonsson, L. J., Palmqvist, E., Nilvebrant, N.-O., and Hahn-Hagerdal, B. (1998). Detoxification of wood hydrolysates with laccase and peroxidase from the white-rot fungus Trametes versicolor. Appl. Microbiol. Biotechnol. 49, 691-697.

Karp, A., Hanley, S., Trybush, S., Macalpine, W., Pei, M. H., and Shield, I. (2011). Genetic improvement Genomes 8, 1051-1060. bills/110/hr6

content were identified, as well as a relationship with ethanol yield. However, it is clear that an increase in cellulose content may increase sugar yield, but does not infer an increase in ethanol production. These findings will spur future research and largescale evaluation of willow germplasm for variation in recalcitrance to promote future breeding efforts aimed at producing new willow cultivars with maximum bioconversion to ethanol without compromising biomass yield potential.

\section{ACKNOWLEDGMENTS}

This work was funded by a grant from the Northeast Sun Grant Initiative to Lawrence B. Smart. The authors thank Deidre Willies and Lucas Ellis for their assistance in performing the hot-water pretreatments and fermentation at Mascoma Corporation. We are grateful to Novozymes for providing the enzymes for hydrolysis. We also thank Kayla Relyea, Jeffrey Springmeier, and Dr. Tim Volk for their assistance on this project.

of willow for bioenergy and biofuels. J. Integr. Plant Biol. 53, 151-165.

Lapierre, C., Pollet, B., Petit-Conil, M., Pilate, G., Leple, C., Boerjan, W., et al. (2000). "Genetic engineering of poplar lignins: impact of lignin alteration on kraft pulping performances," in 215th National Meeting of the American Chemical Society, eds W. G. Glasser, R. A., Northey, and T. P. Schultz (Dallas, TX: American Chemical Society), 145-160.

Lynd, L. R. (1996). Overview and evaluation of fuel ethanol from cellulosic biomass. Annu. Rev. Energy Environ. 21, 403-465.

Mansfield, S. D., Kang, K.-Y., and Chapple, C. (2012). Designed for deconstruction - poplar trees altered in cell wall lignification improve the efficacy of bioethanol production. New Phytol. 194, 91-101.

Martin, E., Bunnell, K., Lau, C.-S., Pelkki, M., Patterson, D., Clausen, E., etal. (2011). Hot water and dilute acid pretreatment of high and low specific gravity Populus deltoides clones. J. Ind. Microbiol. Biotechnol. 38, 355-361.

Martinez-Cabrera, H. I., Jones, C. S., Espino, S., and Schenk, H. J. (2009). Wood anatomy and wood density in shrubs: responses to varying aridity along transcontinental transects. Am. J. Bot. 96, 1388-1398.

Pattathil, S., Saffold, T., GallegoGiraldo, L., O’Neill, M., York, W. S., Dixon, R. A., et al. (2012). Changes in cell wall carbohydrate extractability are correlated with reduced recalcitrance of HCT downregulated alfalfa biomass. Ind. Biotechnol. 8, 217-221.

Ray, M., Brereton, N. B., Shield, I., Karp, A., and Murphy, R.
(2012). Variation in cell wall composition and accessibility in relation to biofuel potential of short rotation coppice willows. Bioenergy Res. 5, 685-698.

Robinson, J., Keating, J. D., Boussaid, A., Mansfield, S. D., and Saddler, J. N. (2002). The influence of bark on the fermentation of Douglasfir whitewood pre-hydrolysates. Appl. Microbiol. Biotechnol. 59, 443-448.

SAS Institute Inc. (2000-2004). SAS 9.1.3 Help and Documentation. Cary, NC: SAS Institute Inc.

Sassner, P., Galbe, M., and Zacchi, G. (2008). Techno-economic evaluation of bioethanol production from three different lignocellulosic materials. Biomass Bioenergy 32, 422-430.

Selig, M., Weiss, N., and Ji, Y. (2008). Enzymatic Saccharification of Lignocellulosic Biomass. Laboratory Analytical Procedure. Golden: US DOE National Renewable Energy Laboratory, 1-8.

Serapiglia, M., Cameron, K., Stipanovic, A., Abrahamson, L., Volk, T., and Smart, L. (2012). Yield and woody biomass traits of novel shrub willow hybrids at two contrasting sites. Bioenergy Res. 1-14. doi: 10.1007/s12155-012-9272-5

Serapiglia, M. J., Cameron, K. D., Stipanovic, A. J., and Smart, L. B. (2009). Analysis of biomass composition using high-resolution thermogravimetric analysis and percent bark content as tools for the selection of shrub willow bioenergy crop varieties. Bioenergy Res. 2, 1-9.

Sluiter, A., Hames, B., Ruiz, R., Scarlata, C., Sluiter, J., and Templeton, D. (2008). Determination of Sugars, Byproducts, and Degradation Products in Liquid Fraction Process Samples. 
Golden, CO: National Renewable Energy Laboratory.

Studer, M. H., DeMartini, J. D., Davis, M. F., Sykes, R. W., Davison, B., Keller, M., et al. (2011). Lignin content in natural Populus variants affects sugar release. Proc. Nat. Acad. Sci. U.S.A. 108, 6300-6305.

Volk, T. A., Abrahamson, L. P., Cameron, K. D., Castellano, P., Corbin, T., Fabio, E., et al. (2011). Yields of willow biomass crops across a range of sites in North America. Asp. Appl. Biol. $112,67-74$.
Yang, B., and Wyman, C. E. (2008). Pretreatment: the key to unlocking low-cost cellulosic ethanol. Biofuels Bioprod. Biorefin. 2, 26-40.

Conflict of Interest Statement: At the time this research was performed, Haowen Xu and David A. Hogsett were employed by Macoma Corporation, a for-profit biofuels company. The other authors declare that the research was conducted in the absence of any commercial or financial relationships that could be construed as a potential conflict of interest.

Received: 23 December 2012; accepted: 03 March 2013; published online: 25 March 2013.

Citation: Serapiglia MJ, Humiston MC, $X u$ H, Hogsett DA, de Orduña RM, Stipanovic AJ and Smart LB (2013) Enzymatic saccharification of shrub willow genotypes with differing biomass composition for biofuel production. Front. Plant Sci. 4:57. doi: 10.3389/fpls.2013. 00057
This article was submitted to Frontiers in Plant Biotechnology, a specialty of Frontiers in Plant Science.

Copyright (c) 2013 Serapiglia, Humiston, Xu, Hogsett, de Orduña, Stipanovic and Smart. This is an openaccess article distributed under the terms of the Creative Commons Attribution License, which permits use, distribution and reproduction in other forums, provided the original authors and source are credited and subject to any copyright notices concerning any third-party graphics etc. 